\title{
Seamlessly transcending the 'Academic Bump' to support the new lecturer in higher education
}

\author{
Amy Bywater* and Sarah Mander
}

*Corresponding author. Faculty of Education, Health and Wellbeing, University of Wolverhampton. Email: a.bywater@wlv.ac.uk.

Amy Bywater is a Lecturer of Physical Education at the University of Wolverhampton, England, United Kingdom. Her experience in practice includes five years teaching across state, academy and independent sectors from ages 2-18 years. This includes leadership roles departmentally and pastorally. Her research interests are currently in perceptions of quality in the field of compulsory education. She is currently engaged in studies for her Doctorate in Education.

Sarah Mander is Course Leader and Senior Lecturer in Special Educational Needs, Disability and Inclusion at the University of Worcester, England, United Kingdom. Her experience in practice includes twenty years spanning practitioner to senior leader roles for the 0-19 age range across the fields of Education and Social Care. This includes work within the statutory, private and voluntary sectors. Her research interests relate to early intervention and preventative work for children, young people and families. She is currently engaged in studies for her Doctorate in Education with Amy. 


\title{
Seamlessly transcending the 'Academic Bump' to support the novice lecturer in higher education
}

\begin{abstract}
This self-reflective paper considers the support mechanisms new lecturers from a teaching background may benefit from upon their entry to academia. The concept of academic identity is explored and the suggestion of a continually evolving professional identity is discussed. Emergent themes of reciprocity and critical friendship, team teaching and personal skills and qualities are examined. The framework for this paper is the introduction of the Teaching Excellence Framework (DfE,2016) and recommendations for Higher Education practice are made in support of this.
\end{abstract}

Keywords: teaching excellence framework, professional identity, quality, mentoring, post-compulsory education, novice lecturer.

\section{Introduction}

This paper stimulates discussion on the informal situated learning for new lecturers transitioning from professional teaching practice to higher education. It develops the concept of an 'academic bump' introduced by Boyd and Harris (2010), which conveys the journey of established, experienced practitioners as they progress to the role of lecturer in higher education institutions (HEI's). The academic bump refers to the stimulus for new lecturers to reflect on and re shape their professional approach to teaching upon entry to higher education. Self-reflection is utilised to explore the marriage of past experiences and professional development with new expectations and requirements. It focuses upon a range of informal support mechanisms which support new lecturers to smooth their academic bump. This contributes to the development of their quality driven teaching practice and stabilises their emerging identity within higher education. Through this reflective practice new professional knowledge is created. 


\section{Methodology}

This self-reflective study has been compiled by the two new lecturer authors. The methods applied are discussion and written reflection. This paper was born from peer to peer discussion in the authors' doctoral community of practice. The community of practice comprises four female and four male students who had studied together for two academic years at the time of reflection. The authors participated in a group discussion which highlighted feelings of uncertainty and an uneasy freshness throughout the doctoral journey. These sentiments resonated with the state of mind experienced during their academic bump. The concept and topic for the article therefore emerged organically through concurrent periods of transition, namely embarking upon new lecturer roles within Higher Education (HE) and continuing study as Doctoral students.

\section{Positionality and Background}

The authors consider themselves relatively new lecturers with a combined four years of lecturing experience within HE. Both achieved Qualified Teacher Status prior to their HE employment, and have several years relevant teaching practice experience. Therefore, they do not classify themselves as new to either teaching or lecturing, or primitive in their careers. Respectively the authors work in differing fields, being Physical Education and Special Educational Needs, Disabilities and Inclusion. At the time of writing both authors worked at the same university, which has since changed. Where the authors have identified positive factors assisting their transition through the academic bump, it is important to address that these positive elements and experiences may differ for other professional practitioner disciplines transitioning into $\mathrm{HE}$ 
lectureship. Their skills, abilities and prior experiences as teachers may differ compared to journalists for example. Thus, the mentoring and support needs of other professional practitioners may vary and is important to consider. The heart of the author's epistemological position is situated within pragmatism, where professional practice is the fundamental driver of their lecturing interests (Creswell, 2009; Pring, 2015). This lens of applied practice is adopted to inform their lecturing roles. Crucially, the currency of their professional practice serves to enrich their individual roles and contribute valuable knowledge within departmental teams, thus fulfilling the learning loop of theory to practice (Kolb, 1984).

New HE lecturers are often referred to as early career academics or novice lecturers (Iglesias-Martinex, Lozano-Babezas and Martinex-Ruiz, 2014; Remmik, Karm, Haamer, and Lepp, 2010). These titles suggest practice experience is secondary to academic knowledge within HEI's; Schön (1987) describes this as privileged status. These terms are also the 'norm' in terms of their use within the field of HE. However, as confidence is a significant determining factor for the development of new lecturers (Daley, 1999), these labels and associated status can create un-necessary hierarchies, under-mining the confidence of new lecturers. This may sabotage the transition process and render the academic bump needlessly bumpier. Furthermore, it lessens the value of earlier contributions to practice for professionals who are not early in their career. It may also be inappropriately utilised to inhibit younger aged professionals as it conveys limited practice experience. In essence, it strengthens a rather subjective, unfounded divide between established lecturers and new lecturers from the outset and consequently serves to impede rather than support an integrated workforce. A diverse workforce provides a broader and more in-depth perspective on various knowledge forms, and crucially the labels afforded to new lecturers may deplete rather than enhance workforce 
cohesion. Segregation between practice and academia is contradictory to the criteria of the Teaching Excellence Framework, referred to as the TEF (DfE, 2016), which seeks to ensure students achieve their professional goals and are equipped to progress to highly skilled employment. Therefore, practice experience and academia should continue to be valued as separate proficiencies in addition to their dynamic and unique relationship which provides significant contribution to quality in teaching and learning practice.

\section{Academic Identity}

There is a distinct period of time where the position of 'insider-ness', (Burns, Fenwick and Schmied, 2012) in terms of knowledge and skills as new lecturers, and as practitioners is retained. The fast pace of change within educational policy renders the new lecturer an outsider from professional practice very quickly and therefore capitalising upon insider status can enhance the quality of practice in higher education. New lecturers emanating from practice can utilise their currency of practice, a hands on experiential proficiency, to inform their higher education roles. The opportunity to bring implicit knowledge and skills directly from practice is unique as any future forays into practice will be undertaken as outsiders.

The culture shock which the new lecturer experiences when entering a new community of practice should not be under-estimated. The values and knowledge base acquired within new roles commands emotional and practical investment to establish a robust academic identity (Anderson, 2009, in Jones, 2012). Jones (2012) recommends time is provided by organisations for new lecturers to develop and reflect, and this can support the development of academic identity. Boyd and Harris (2010) acknowledge that newly appointed lecturers are hampered in their quest to develop academic 
identities by the workplace context, attempting to retain earlier professional identities whilst grappling with their emerging academic identities. Perhaps therefore it is wise for the new lecturer to immerse themselves in an identity which is continually evolving, drawing upon the strengths of both professional practice and academic requirements. Overall, an osmotic combination of both identities could offer a seamless transcendence of the academic bump.

Professional practitioners transcending the world of academia are required to adapt their professional identity in a range of ways. There is the obvious shift to androgogical learning, which in itself is a mammoth and unfamiliar task. Previous experience of teaching and learning can help to smooth this part of the academic bump; however, experienced teachers can still find some difficulty in adjusting to working with adult learners. This is supported by formal situated learning opportunities for continuing professional development (CPD), such as the post-graduate certificate in higher education and professional practice (PGCert) and fellowship of the higher education academy (FHEA) which contributes to quality assurance of teaching. The introduction of the TEF (DfE, 2016) affirms the requirement for recognised higher education teaching qualification. In support of this, it formalises the necessity for teaching observations. Whilst this may help the new academic to establish their higher education identity, perhaps through insightful feedback and critical friendship, the TEF is however contestable. It has no direct way of identifying or measuring teaching quality. Wood and Su (2017) researched academics' perspectives of teaching excellence and found they feared quantitative measurement of teaching quality by the TEF could reduce excellence rather than enhance it. Further, these fears mirror the concerns of teachers in school and further education (FE) sectors regarding the Office of Standards in Education's (OFSTED) quantifications. 
However, informal support can also be extremely beneficial to support development of academic identity. Day, Kington, Stobart and Sammons (2006) acknowledge the fluctuation of teacher identity dependent on life events, such as points of career transition. This career transition is examined through self-reflection on the authors' journeys into careers within a widening participation higher education institution and the informal situated learning which enabled and enhanced their experience. It explores the merits of reciprocity and critical friendship, team teaching and personal skills and qualities to aid the new lecturer's development.

\section{Reciprocity and Critical Friendship}

The first consideration of reciprocity and critical friendship relates to time constraints of staff in higher education and the TEF requirements to quantify teaching intensity (DfE, 2016). Quantification of teaching intensity does not necessarily facilitate collegiate mentoring capacities; it does not prioritise development of new lecturers. The new lecturer can progress the quality of their teaching and the formation of their academic identity with appropriate informal support, thus contributing to teaching excellence. Schön's (1987) suggestion that the balance of value between formal education and practice experience weighted more towards academic status is still relevant today. This does little to smooth the academic bump, but informal and collegiate mentoring can help to ease the transition.

The authors experienced collegiate mentoring as informal situated learning. It was voluntarily provided by senior lecturers because they could empathise with the

plight of the new lecturer having made similar transition from practice to academia. However, it cannot be assumed that this support is readily available for all new 
lecturers. Critical friendships naturally followed as a result of developing trust through sharing vulnerabilities. The presence of these vulnerabilities with direct relation to identity is also acknowledged by Day et al. (2006). This essentially demonstrated humility and mutual respect for the merging of new and senior lecturers' expertise. Senior Lecturers' time was willingly given and was not part of their allocated workload. Moreover, senior lecturer's preparedness to express their own vulnerabilities may not routinely occur. Having made such a heart-driven decision to invest in the development of new lecturers, the difficulty of sustaining this time commitment arose. Passion for the subject and for teaching and learning invigorated the mentorship and ensured it did not wane. This was energised by the new lecturers' currency of practice and also through applying the senior lecturers' experience of theoretical concepts.

The emphasis upon student feedback is increasingly important as the TEF (DfE, 2016) embeds. The authors evidenced from summative evaluation that students valued team teaching. This included 60 end of module evaluations completed utilising anonymous questionnaire feedback schedules, which reported improved sense of selfefficacy, engagement, retention and confidence in their academic abilities. Students attributed these positive outcomes to high quality teaching and learning achieved through combined lecture delivery from established and new lecturer. The barriers faced by students resonated with the new lecturers, who found linking new theoretical perspectives to practice was a developing skill alongside teaching practice. Overall, it is fair to summarise that students' learning was enhanced and improved through collegiate mentoring. For all stakeholders involved there is value in reciprocal learning providing that HEI's invest time to refresh and update teaching and learning practices. Workload allocation for established academics could therefore routinely protect time for senior lecturers to provide regular informal support for new lecturers. 


\section{Team Teaching}

Team teaching has been described as innovative, but not simple. It involves the pooling of talents to impart course content, knowledge, value and skills (Buckley, 1999). The richness of diverse perspectives requires careful consideration and planning, however, Davis (1996, p.2) states the reward of working together 'will make a greater contribution than the 'sum' of the participants working alone'. The authors' experience is that team teaching capitalised upon both the new lecturers' currency in practice and the senior lecturers' academic experience. Generic practical teaching and learning activities were utilised during team teach to generate improved knowledge and understanding of theoretical models. Students were encouraged to verbalise and communicate the ways in which theory was applied to practice during their taught sessions with improved synthesis. Through purposeful cognitive inquiry incorporating question and answer techniques from both theoretical and practical perspectives, a higher order of thinking was achieved (Anderson and Krathwohl, 2014; Clynes, 2009). Students shared with the teaching team their light bulb moment when clarity emerged regarding the importance of theoretical concepts and how they underpin practice. They had previously been unable to make these links.

The success of team teaching to contribute to the induction of the new lecturers can be attributed to shared visions of the teaching teams. It is recognised however, that harmonious vision is not always possible or sought and this may render team teaching problematic. Although shared visions were present, the team possessed differing ontological and epistemological perspectives. Some lecturers held a more constructivist stance, while others applied a more pragmatic approach. Constructivists may seek quantifiable, definite knowledge and more objective findings (Pring, 2015; Duffy and Chenail, 2008). However, a pragmatic epistemological position underpinned all 
practices which strengthened shared visions and approaches to team teaching. The pragmatic approaches of the new lecturers included the richness of ideas related to currency of practice and real world questions which related directly to what students could apply through their own teaching. The constructivist views of the experienced lecturer enabled students to combine rich practice ideas with academic concepts which underpinned that practice. Bourdieu and social constructivist ideas are evidenced in the creation of this very comfortable working environment for the teaching team; where there was greater empathy for and engagement by the students. This explained by the teaching team's shared values related to the subject areas, similar social experiences, interests (Laberge and Kay, 2002) and the fortune of similar experiences moving into the HE sector.

The power dynamics and potential for power imbalance between those involved with team teaching can provide both benefits and pitfalls for practice. Where the new lecturer is treated as novice, power imbalances can become more prevalent (Giroux, 2011). Knowledge of power imbalances and how to manage them may ease the academic bump, utilising structured reflection by the teaching team as a tool for empowerment (Ryan, 2005). This reflection can lead to greater insight and further improvement in the quality of teaching practice, particularly when undertaken collectively with more experienced colleagues. The authors capitalised upon opportunities for combined reflective practice, ensuring that each team teach session was evaluated by all lecturers involved, identifying techniques to improve future teaching and planning accordingly. They were given equality of opportunity to express views and opinions based upon their current practice experience and its transference to higher education teaching. Crucially, the authors describe the equality afforded to them as new lecturers an empowering process which played a significant factor in increasing 
their confidence and sense of self-efficacy. This emphasises the importance of informal collegiate mentoring and guidance to provide value added support for new lecturers in addition to formal professional development. However, where power dynamics are at play between new and established lecturers, the new lecturer may be disempowered and lack confidence to raise emergent issues. The authors readily acknowledge and express gratitude for this voluntary support during their initial stages of academic careers, and attribute their successful transition to the unique perspective of colleagues who have also undertaken this academic journey.

It is recognised that in some circumstances power imbalances within the teaching team may shift, particularly when the professional entering academia possesses more experience in practice than established higher education lecturers. This may result in established academics feeling unjustifiably threatened. The ensuing environment of team teaching may cause new lecturers to feel inferior, regardless of the extent of their practice experience. These vulnerabilities not only have the power to reduce the quality of teaching practice, but also to fragment the altering identity of the new lecturer, whose self-image, self-esteem, job motivation, task perception, stability and future perspective are adjusting as part of their professional selves (Day, et al. 2006). Iglesias-Martinez, et al. (2014) found their participants offering the feeling of 'working on his or her personal islands of knowledge' (175). New lecturers finding themselves team teaching in disharmony because of such power imbalances may need to harness their practice experience of building effective, collaborative working relationships. They would be wise to invite established lecturers to re-visit their own induction into academia, focussing upon their knowledge, wisdom and experience gained and to celebrate their achievements. This can initiate a more empathic team teaching situation which is conducive to more positive experiences for all involved. 
Upon reflection, where students found developing an in depth understanding of theory challenging, they were helped to overcome this hurdle by synthesising theory to practice. The obvious underpinning of theory to practice is not always known or recognised by students in their earlier learning. If the concept that academia is considered superior to practice perpetuates within higher education (Schön, 1987), a perpetual state of confusion for students and a lack of ability to apply learned theory to practice will prevail. The learning gain and distance travelled referred to in the TEF (DfE, 2016) can be hampered if students perceive theoretical models incomprehensible and mystifying and this can consequently contribute to poor retention and underachievement.

\section{Personal Skills and Qualities}

Personal skills and qualities of lecturers are an essential component of their academic identity. Boyd and Harris (2010) explain that tensions with the workplace context of HEI's cause new lecturers to covet their credibility and identity as practitioners, instead of adopting academic identities. Whilst this may be construed as a negative quality, almost a holding onto the past and un-willingness to embrace the new, the skills and experience gained from practice should be seen as an important contribution to the academic context. There are elements of transferability with many skills which provide comfort during the transition process. Day (2005) refers to some of these skills as 'Craft Knowledge'. This craft knowledge relates to the professional knowledge which is gained through experience prior to entry into higher education 
lecturing roles. Definition of these 'crafts' or skills can be elusive, despite the knowledge that they are situated in the heart of teaching excellence and can be relevant and inter-changeable for all types of professionals moving into new lecturer roles. Not only can these ease the academic bump, but may also encourage the new lecturer to seek and observe new crafts relevant for a different education context. This can be achieved through being part of an effective teaching team and by drawing on senior lecturers' experience.

The authors' reflections are that initially the informal and more transferable skills brought from teaching practice were more heavily relied upon at the start of their lecturing roles. This dependence arose partially because formal situated learning was not immediately available whilst the more familiar skills and qualities were already refined, organically embedding into their new roles with unconscious ease. Associated skills with teaching roles identified by Jones (2005) included counselling, facilitating, researching, supporting and educating were transferred from practice. However, the realisation and acceptance that lecturing itself is a skill (Clynes, 2008) requiring practise offered the authors a degree of humbleness and humility alongside further acceptance that all answers cannot be known. This could be suggested as aspirational best practice, as this willingness may not be the norm in teaching teams. Previous practice or teaching experience makes these initial hurdles a tried and tested process in earlier careers, but are newly characterised and re-shaped hurdles in HEIs. Traversing these HEI hurdles helps the new lecturer achieve familiarity with their new role and different institution, and successfully navigate the academic bump. New lecturers with more stable or perhaps deep-rooted practice identities may find it more difficult to adapt to a new context and the transition may initially incite personal and professional instability (Day, et al. 2006). The authors report that pressures to construct and sustain a stable HEI 
identity was eased by the aforementioned reciprocity and critical friendship and practical support in team teaching, with role modelling of established academics playing a crucial and positive factor. This helped alleviate the risk that through HEI transition their professional identity could become discontinuous and fragmented (Day, et al. 2006). The authors also reflect that their continual post-graduate study prior to becoming lecturers enabled them to form a basic academic identity whilst supporting their professional practice. Their position as lifelong learners provided them with one of the greatest skills that there will always be something to learn.

The personal quality of knowing oneself, 'knowledge of the self' is classified as a survival technique for new lecturers and an essential skill in respect of how teachers understand the nature of their work (Day et al. 2006, 603). The entwined relationship between professional and personal selves is unavoidable due to the personal investment teaching often requires (Day et al., 2006). Reflecting upon early lecturing experience, the authors' professional and personal selves became more unified and provided increased stability. Retaining the 'who I am' in terms of delivery as a new lecturer and also in previous professional practice was of paramount importance to the authors. This required a good level of confidence in order to be true to oneself. The ability to be open and transparent enabled respectful, cooperative and trusting professional relationships to develop between new lecturers and established academics. It set a virtual standard, or principle, by which the new lecturers wished to be perceived. In return, there was willingness on parts of both the new lecturers and critical friends to offer constructive feedback, strong open-mindedness, encouragement and nurture. Crucially, where the new lecturers offered practical insight, the experienced academic strengthened this with theoretical links. 
The most influential personal qualities shared were the willingness of both parties to offer humility and complete honesty with feelings, thoughts on particular sessions and planning discussions which all ultimately built strong foundations for the critical friendship. This provides a firm foundation for quality in teaching and learning. A resounding skill and personal quality demonstrated by new lecturers was the high quality of student interaction, which established academics highlighted as a key strength of their early lecturing practice. Some of the established academics reflected upon their more distant professional relationships with students, stimulating discussion and resulting in changes in their approach to student/lecturer interaction. The privileges and difficulties experienced by new lecturers were mutually understood, generating trust and empathy which subsequently increased confidence levels of the authors.

\section{Conclusion}

It is acknowledged many obstacles can be experienced upon transition from practice to academia (Boyd and Harris, 2010; Iglesias-Martinez, et al. 2014; Jones, 2012). This reflective paper has identified strategies and practical techniques of informal situated learning which can ease the accompanying academic bump. A recipe comprising durable professional identity, reciprocity and critical friendship, team teaching, a mix of transferrable skills and qualities with newly acquired lecturing proficiencies, supported by understanding of the dynamics and power imbalances associated with the induction of new lecturers has been formulated; providing insight and recommendation for practice. There are important transitional considerations for both new lecturers and HEIs, particularly in light of the TEF (DfE, 2016). In particular, investment in informal collegiate mentoring support from established lecturers with new lecturers is advocated 
as a reciprocal benefit and values both practice and academic knowledge and experience.

Further research in this area may include more in-depth narrative inquiries with interviews between the new lecturers and key informal yet influential figures fulfilling mentor-like capacities, without the formal title (critical friendships). It is noted that some HEIs are developing communities of practice dedicated to new lecturers, and this is welcomed. Throughout this writing process, the authors improved their selfawareness and understanding of their academic roles and identities. Sharing stories helped galvanise previously unexplored thoughts and feelings; definitive themes emerged and conclusions were drawn. These insights may help to further reduce the academic bump for new lecturers as well as offering a high degree of reciprocity for parties involved. They have the potential to enhance the quality of teaching practice and ultimately the student experience.

\section{References}

Anderson, J.K. 2009. The Work-Role Transition of Expert Clinician to Novice Academic Educator. Journal of Nursing Education 48 (4): 203 - 208

Anderson, L. and Krathwohl, D. 2014. A Taxonomy for Learning, Teaching, and Assessing: A Revision of Bloom's Taxonomy of Educational Objectives Essex: Pearson Education Limited

Boyd, P. and Harris, K. 2010. Becoming a university lecturer in teacher education: expert school teachers reconstructing their pedagogy and identity. Insight 36 (1-2): 116. 
Buckley, F. 1999. Team Teaching: What, Why and How? London: SAGE

Burns, E. Fenwick, J. and Schmeid, V. 2012. Reflexivity in midwifery research: The insider/outsider debate. Midwifery 28 (1): 52-60.

Creswell, J.W. 2009. Research Design: Qualitative, Quantitative, and Mixed Methods Approaches. $3^{\text {rd }}$ Edition. London, SAGE.

Clynes, M. P. 2009. A novice teacher's reflections on lecturing as a teaching strategy: covering the content or uncovering the meaning. Nurse Education in Practice 9: 22-27.

Daley, B. 1999. Novice to Expert: An exploration of how professionals learn. Adult Education Quarterly 49 (4): 133-147.

Day, T. 2005. Teachers' craft knowledge: a constant in times of change? Irish Educational Studies, 24 (1): 21-30.

Day, C., Kington, A., Stobart, G. and Sammons, P. 2006. The personal and professional selves of teachers: stable and unstable identities. British Educational Research Journal 32 (4): 601-616.

Department for Education (DfE). 2016. Teaching Excellence Framework: Year 2 Specification. DOI: https://www.gov.uk/government/publications/teaching-excellence$\underline{\text { framework-year-2-specification }}$ 
Duffy, M. and Chenail, R. J. 2008. Values in Qualitative and Quantitative Research. American Counselling Association 22 (53): 22-38.

Giroux, H. A. 2011. On critical pedagogy. New York: Continuum International Publishing Group.

Iglesias-Martinez, M.J., Lozano-Cabezas, I. and Martinez-Ruiz, M. A. 2014. Listening to the Voices of Novice Lecturers in Higher Education: A Qualitative Study. International Journal of Teaching and Learning in Higher Education 26 (2): 170-181.

Jones, R. 2012. Reflecting on the Transition from Practice to Education - The Journey to Becoming an Effective Teacher in Higher Education. Journal of Pedagogic Development 2 (2): $2-12$.

Kolb, D. A. 1984. Experiential Learning: Experience as the Source of Learning and Development. Englewood Cliffs, New Jersey: Prentice-Hall.

Laberge, S. and Kay, J. 2002. Bordieu's sociocultural theory and sport practice, in Maguire, J. and Young, K. (Eds). Theory, Sport and Society. Oxford, Elsevier. 239-266.

McLeod, J. 2016. Narrative Case Studies and Practice-Based Learning: Reflections on the Case of "Mr. R". Pragmatic Case Studies in Psychotherapy 11 (2): 239-254.

Pring, R. 2015. Philosophy of Educational Research. ( $3^{\text {rd }}$ Ed). London, Bloomsbury. 
Remmik, M., Karm, M., Haamer, A. and Lepp, L. 2010. Early-career academics' learning in academic communities. International Journal for Academic Development 16 (3): 187-199.

Ryan, A. 2005. Teacher development and educational change: empowerment through structured reflection. Irish Educational Studies 24 (2-3): 179-198.

Schön, D. A. 1987. Educating the Reflective Practitioner. San Francisco: Jossey-bass, in, Manen M.V. 1995. On the epistemology of reflective practice, Teachers and teaching 1 (1): 33-50.

Wood, M. Su, F. 2017. What makes an excellent lecturer? Academics' perspectives on the discourse of 'teaching excellence' in higher education. Teaching in Higher Education 22 (4): 451-466. 